\title{
I. Scientific signalling and safety at sea
}

\author{
Prof. John Joly M.A. D.Sc. F.R.S. F.G.S.
}

To cite this article: Prof. John Joly M.A. D.Sc. F.R.S. F.G.S. (1918) I. Scientific signalling and safety at sea , Philosophical Magazine, 36:211, 1-36, DOI: 10.1080/14786440708635799

To link to this article: http://dx.doi.org/10.1080/14786440708635799

曲 Published online: 08 Apr 2009.

Submit your article to this journal

Џ Article views: 2

Q View related articles ¿ 


\title{
PHILOSOPHICAL MAGAZINE
}

\author{
AND \\ JOURNAL OF SCIENCE.
}

[SIX'TH SERIES.]

$J U L Y 1918$.

I. Scientific Signalling and Safety at Sea. By Prof. Jонм JоLY, M.A., D.Sc., F.R.S., F.G.S.*

[Plate I.]

\section{Approaching the Coast.}

THE most common-place and often one of the most urgent of the problems which confront the sailor is the determination of his position upon near approach to the coast. We may, indeed, say that the determination of latitude and longitude at any time is solely in preparation for that stage of the voyage when the ship draws near the land. The special difficulties sometimes attending the solution of this problem are known only to those who have endeavoured to make a landfall or pick up a lightship in wild or thick weather or in the calm obscurity of a fog.

In our Admiralty Sailing Directions or Pilots we read that there is no help for the sailor in a fog save unreliable fogsignals and the use of the lead. The whole passage as ordinarily given is intimately connected with our subject and highly instructive. "Sound is conveyed in a very capricious way through the atmosphere. Apart from wind, large areas of silence have been found in different directions and at different distances from the fog-signal station, in some instances even when in close proximity to it.

* Communicated by the Author. Being the Tyndall Lectures delivered at the Royal Institution, April 1918.

Phil. Mag. S.6. Vol. 36. No. 211. July 1918. 


\section{"The Mariner should not assume-}

a. 'That because he fails to hear the sound he is out of hearing distance.

b. That, because he hears a fog-signal faintly, he is at a great distance from it.

c. 'That because he hears the sound plainly he is near it.

$d$. That, because he does not hear it, even when in close proximity, the fog-signal has ceased sounding.

$e$. That the distance from and the intensity of the sound on any one occasion, are a guide to him for any future occasion.

Taken together, these facts should induce the utmost caution in closing the land in fogs. The lead is generally the only safe guide."

It would be, of course, entirely wrong to conclude that such drastic warnings are intended to imply the general worthlessness of aerial sound signals. It is probable that the disuse of such signals wonld not find favonr. Our present purpose is rather to consider additional aids to navigation whereby the sailor escapes the special dangers arising from the failure of aerial fog-signals, and is supplied with other signals at once more reliable, heard at greater listances, and giving him information beyond the power of atrial tog-signilis to conrey. Such modern methods of signalling are hased on recent advances in science.

We shall consider first what may be called "synchronous signalling," that is the use of signals propagated in different media but timed so as to start at the same instant.

The principies of synchronous signalling have for long. formed a part of familiar household science. When timil people see the flash of lightning and hear the crash of thunder they feel reassured when they perceive an appreciable interval separating the one phenomenon from the other. On the other hand, when both occur together they infer, and rightly so, that there is more danger. And most people are aware of the principle underlying this inference. If the seat of the electric discharge, the flash itself, in fact, is remote, the sound originated by it, i.e. the thunder, takes an appreciable time to reach the ear. Travelling nearly 1100 feet in a second, this time interval may amount to several seconds. On the other hand, the velocity of propagation of light is so enormous that we may consider that we see the flash at the very instant of its occurrence however remote it may be placed. Hence if one second intervenes between the moment of seeing the flicker of the lightning and hearing 
the thunder, the scene of the discharge must be about 1100 feet distant. If two seconds elapse the distance is 2200 feet, and so on. The whole theory of synchronous signalling is involved in this time-honoured chapter of domestic science.

For suppose a gun to be fired from a lightship guarding some peril of the coast, and simultaneously with the explosion a light be flashed from the lantern of the lightship ; a vessel afar off sees first the flash-at the very instant of its occurrence-and later she receives the sound of the gun. For every second of interval between the seeing of the flash and hearing of the gun about 1100 feet may be allowed. If the interval was $3 \frac{1}{2}$ seconds then the ship is $1100 \times 3 \frac{1}{2}=$ 3850 feet distant from the lightship. But this is just the information which the mariner approaching at night values above all other and which is most conducive to his safety. It gives him the means of determining not only his distance from the danger guarded by the lightship but also it gives him his actual position.

On the existing system of coast signals the mariner is given the light and the sound in no way co-ordinated one with another. Each of these signals, therefore, is aimed at accomplishing the same thing, i.e. telling the sailor the direction in which the danger lies. They give him. also, some idea of his distance as being within the limits of visibility or andibility of the one or other of the signals. But the inference of distance is so affected by weather conditions as to be uncertain and even deceptive in character. It is possible to hear the gun of the lightship and to think it sometimes close by and again far off, and for the direction of the sound to remain quite uncertain. The bearing of the light is indeed certain when it is visible. Our coast signals, as at present ordered, therefore, give the mariner at best the bearing of the danger and but a rough and uncertain indication of distance. But the synchronized signals we have described give him not only the bearing but a determination of distance sufficiently accurate to enable him to fix his position.

In order to understand this clearly let $l$ (Pl. I. fig. 1) mark the position of the lighthouse. The circle struck round it is to the radius $d$, which is the distance as determined by the synchronous signal. The ship must be located somewhere on this circle. If now the bearing of $l$ from the ship is S.W., the ship is at $x$. It cannot be anywhere else. And evidently the bearing of the light and the distance must, similarly, in every case give the sailor his position.

There are objections, as we have seen, to the use of sound 
siguals propagated through the atmosphere. They are difficult to pick up in stormy weather ; more especially when the wind is blowing from the ship towards the source of sound. The sound appears to be weakened by these conditions, and if the wind is making much noise on the ship it may not be heard at a sufficient distance. It has to be listened for in the open. A more serious objection is the strange and, fortunately, not very common phenomenon of silent areas as referred to in the Admiralty Sailing Directions quoted above. A ship may be well within the range of audition; the weather may be calm, even windless, and the sound may be mute over certain areas. The phenomenon is a remarkable one, and a full explanation cannot be said to exist. It has been investigated by Tyndall and by Lord Rayleigh. The nature of the sound seems without influence. Even the very beautiful elliptic trumpet of Lord Rayleigh, whereby the sound is caused to spread laterally and its vertical dissipation prevented, cannot counteract the evil when the necessary conditions prevail. There appears to be such a deviation of the sound as causes it to rise and arch over certain areas. It may be heard ten miles from the source and be entirely mute close to it. Or, again, when approaching the source we may find more than one silent, area as if the sound waves followed a sinuous path, rising and again sinking to the surface of the sea. In such cases the value of the synchronization may be lessened in another way. The sound which is heard outside a mute area will not have travelled directiy from its source. The question is: how much has its journey been lengthened? Probably the increase of distance is not much. Nevertheless there may be appreciable error here. Again, the use of lightflash has, of course, the drawback of being invisible in fog or thick weather. Hence only under certain conditions and at certain times is the combination of synchronized light and sound signals of value.

Notwithstanding these limitations such a system would undoubtedly prove very useful. To condemn it in advance is as senseless as to condemn all our lighthouses and fog-signal stations because conditions arise when they are useless. And it should be considered by all responsible anthorities if, for the general use of small craft-fishing boats, small coasters, and the like-a system of buoyage based on light-flash and bell-stroke would not be valuable. We may profitably consider here, before going further, how such a system may be worked so as to meet the requirements of untrained observers. 
Automatic bell-buoys are common around our coasts at the present time; and buoys which show an occulting light are also common. Very often both functions are performed by the one buoy. The bell-stroke is operated by energy derived from the motion of the waves. There is, even under conditions of apparent calm, considerable energy available from this source. It is not necessary for the bell to be struck at regular intervals, but it is of importance that the blow upon the bell should always be given with the same force, so that the sound emitted should be of uniform loudness. We may suppose, then, that the up and down movements of the buoy, bowever gentle and slow, are resisted by a horizontal vane immersed in the water beneath. 'l'his vane, as it oscillates respecting the buoy with the rise and fall of the latter, compresses, by means of a ratchet, a spring which when stressed to a certain degree is released and its stored energy expended in actuating the hammer. As we shall see later very similar mechanism is in frequent and successful use. We have, then, a bell-stroke in air, at intervals, and made with a certain constant force. It is matter of observation that even in calm weather three or more strokes will be given per minute. We would require, in fact, a certain controlling mechanisin limiting the number of strokes to, say, 3 per minute.

I assume now that a light-flashing system is also installed upon this buoy similar to miany of the blinking or occulting lights marking sand-bank or other danger close to the shore. A connexion between the mechanism actuating the hammer and that causing the occultation of the light is arranged, of such a nature that simultaneously with the stroke of the bell there is a sudden flare-up of the light, or sudden luminous flash, followed by a succession of flashes spaced at short regulated intervals.

We can so order the signals that the sailor making harbour requires no stop-watch to measure the lag of the sound upon the light signal. The light flashes, repeated at regular intervals, themselves afford the measure of the lag of the sound waves. For suppose 20 successive light flashes spaced at such an interval of time as the sound takes to travel one-tenth of a nautical mile-that is one cable. Flashes so timed are easily counted, this interval $\left(0^{\prime \prime} .53\right)$ being very little over one-half second. Then if the first flash is emitted 0.53 second later than the instant of the first bell-stroke, when the first flash reaches the ship the sound has already travelled one cable, and if the sailor is at the distance of one cable he hears the stroke of the bell at the instant at 
which he sees the first light-flash. If the sound comes to him along with the 2 nd flash he must be 2 cables distant, and if with the 10th flash he is 10 cables from the buoy. Thus he hais only to count up the flashes till he hears. the bell, and the result is the number of cables which separate him from the buoy.

The value of this buoy to small craft is more especially evident when we remember that such craft aro to a great extent debarred from the use of wireless and submarine signals. Expert knowledge denied to the humble skipper is required for the care and use of the former; and the small dranght reduces serionsly the efficiency of the latter.

We can pieture now the working of this simple and inexpensive substitute for the lightship on dark and wild nights. When the sililor picis up the light he is, maybe, some three or four miles away. It may be of serious importance to determine his distauce: either for laying his con'se along the coast or the making of harbour. He sees the distant flash and he knows it is safe to stand in till he hears the bell. Presently he picks this up. He now waits for the next group of flashes and he counts them as they come in :one, two, three . . . . till he hear's the clang of the bell. It may cone with the 15th flash. If so he knows he is $\mathbf{1 5}$ cables or $1 \frac{1}{2}$ mile distant. Nothing can be simpler. As mere indicator of direction the light-and-bell buoys of our consts possess nothing like the value of this synchronized light-and-bell buoy. The frst cost would be smull and the cost of upkeep, compared with that of a lightship, trifling.

Modern advance has given us signals of other kinds which -as all know-have al leady afforded invaluable help to the sailor. Wireless is a sort of light signal against which fog and snow and thick weather are powerless. Its velocity of propagation is practically instantaneous. Submarine signalling utilizes the propagation of sound through water, and this may be regarded is furnishing a sound signal which also is unaffected by weather conditions. The sound of a bell-stroke beneath the water travels at about 4800 feet (1463 metres) per socond. Hence the submarine bellstroke lags behind the wireless "dot" by 1-2 seconds for each natical mile traversed, if both signals are started -together. If an air-sound and a water-sound be started synchronously from the same point, the lag of the atmospheric sound on the submarine is $4: 3$ seconds for each nautical mile traversed.

For the benefit of those unacquainted with recent advances in this branch of applied science a word may be said here 
about the advent of submarine signalling. The idea is really an old one. It has long been known that sound travels under water with remarkably little loss of clearness and intensity. In 1826 Collodon and Sturm carried out their well-known experiment on the Lake of Geneva. The object of this experiment was to ascertain the velocity of sound in water. A submerged bell was used. The hammer which struck the bell was so connected with a trigger above the water that a charge of gunpowder was ignited at the instant of the striking of the bell. An observer in a boat at a certain measured distance listened at a hearing trumpet immersed in the lake. He heard the sound of the bell as. propagated through the water and saw the flash of the explosion as propagated through the rether. Assuming the velocity of the latter to be comparatively infinite, the interval between the seeing of the flash and the hearing of the bell affords the velocity of sound in water. Obviously we can reverse the objective of this experiment. Knowing the velocity of sound in water and measuring the interval of time elapsing between the flash and the sound, we can determine the distance over which the latter has travelled.

The fact of the easy propagation of sound through water is an old discovery of the diver. The perfect audibility is even startling. It is said that a lost watch, which being watertight continued to go, was recovered by a diver tracing the tick of the watch to its source *.

Many years ago I experimented on the audibility of explosive sound signals beneath water. The object in view was to test a method of determining the depth beneath a ship travelling at full speed, by the dropping of a sinker which would detonate a small charge of explosive on contact with the bottom. The time interval between the moment of releasing the sinker and hearing the explosion, knowing the rate of descent of the sinker, gives the depth with sufficient accuracy. In order to test the distance to which the

* We may note parenthetically the curious fact that marine animals do not seem to avail themsel res of this property of the medium in which they live to the extent we might have expected. The organism appears to be ever ready to avail itself of every advantage which the nature of the medium offers it. In this case avidence that it does so seems wanting. True it may develop listening orgaus but, whether it seeks to preserve the secrecy which is the chief protection of the submarine, or whether its silence benefits it in some other way, the fact remains that the sounds emitted by rattlesnake or cricket do not appear to be emulated by fish or crustacean. Our sensitive microphones must have discovered the existence of any such devices. The matter deserves further investigation. 
sound of the explosion would be propagated, small metal cartridges containing about half an ounce of gunpowder were exploded at the bottom off the coast of Dublin. The explosion was heard with astonishing distinctness at least a mile away in boats unprovided with any form of soundreceiving apparatus. The sound was perceived in an open boat as an apparent blow or percussion against the bottom of the boat.*

The apparatus both for sending out and receiving submarine signals has been developed to a high pitch of reliability, largely due to American initiative and to the scientific methods of the Submarine Signal Company. As may be imagined, a long period of suggestions, initial experiments, and abortive patents preceded the existing apparatus. The submarine bell has taken its place as a standard means of sound-production, although invention in other directions has produced wonderful results as we shall see. Repeated trials of various types of bell have resulted in a pattern weighing $220 \mathrm{lb}$., made of bronze, and with a period of 1215 vibrations in water. This bell is now doing duty in erery part of the world : on lightships ; bell buoys ; on the bottom of the sea ; at the pier-head or on ships.

The striking mechanism is contained in a cylindrical bronze case attached above the bell (Pl. I. fig. 2). The striking is generally operated pneumatically. A twin rubber-hose pipe connects the bell, which is suspended by a chain at a depth of about 18 feet, with a reservoir of compressed air on the lightship, or shore station. This reservoir is kept pumped full of compressed air by means of a small oil or steam engine. The mechanism for operating the bell-stroke is simple. An air-driven code regulating valve forms part of the overwater plant and determines the frequency and character of the submarine signal. Some 30 or 35 strokes may be struck per minute. In 1906 the United States Government tested five of these bells for 51 days; the ringing being continuous, six seconds between the blows. Their introduction into England was slower than in the States. The British Admiralty tested the system later that same year and reported as follows: " ... The submarine bell increases the range at which the fog signal can be heard by a vessel, until it approximates to the range of a light-ressel's light in clear weather, and moreover its bearing can be determined

* A patent was obtained at the time (1890) for this form of sounding machine. Failing any encouragement from the Admiralty, it was abandoned. Some years later the method was independently re-patented by an officer in H.M. Navy. 
with quite sufficient accuracy for safe navigation in fog, from distances far beyond the range of aerial tog signals if the vessel is equipped with receivers. If the light-vessels round the coast were fitted with submarine bells it would be possible for ships fitted with receiving apparatus to navigate in fog with almost as great certainty as in clear weather." In spite of this report the multiplication of submarine bell stations was slow in England. 'The first was installed off the Mersey in December, 1906. The Irish Lights Commissioners placed a submarine bell on the Kish Bank Lightship in 1909.

The submarine bell is in some cases operated electrically; more especially for use off the coast on the floor of the sea. A power station on the coast supplies the requisite current. 'The bell is suspended from the apex of a steel tripod about 25 feet high and weighing 3 tons, a cable being taken ashore. The depth varies down to 25 fathoms. Such a bell is located off the Stack Lighthouse, Holyhead. The frequency of the bell-stroke is controlled by rotary time switches. In the United States this system came into use as early as 1901 .

Finally the submarine bell-buoy claims our attention. This is a simple and effective signalling machine and one which may be maintained at small annual cost. The buoy carries the bell and its simple mechanical mechanism housed beneath it in a boiler-plate receptacle which is open below, the bell alone partly protruding. 'Thus the mooring chain cannot foul the bell or its operating mechanism. The motive power is entirely derived from the wave energy of the sea. The mechanism is such that the energy imparted by the rising and falling of the buoy to a hinged vane immersed beneath is accumulative. A spring is compressed by the movement of the buoy, whether this be up or down. Each oscillation thus compresses the spring a little more till when a certain compression is produced the spring is released and in the act of release causes the hammer to strike the bell. The uniform intensity of the blows is thus secured. The frequency of the strokes depends on the state of the sea, but, as already mentioned, is never less than three or four strokes per minute. To secure the mechanism against the rusting effects of sea-water the chamber holding it is filled with oil; any leakage of which is made good from a small tank above.

The recognition of sound by those on the vessel presents a problem of equal importance with that which we have been considering. It is requisite not only to receive the sound, but to receive it in such a manner as to enable the sailor to determine the direction from whence it proceeds. 
The earlier attempts were directed mainly to develop listening devices which could be towed astern of the ship or could be attached without to her sides. It was expected that the noises on the ship would render any other mode of listening ineffective. Iater results showed that listening to such aconstic vibrations as the walls of the ship pick up from the sea is the most effective method. This method, too, permits of determining the direction whence the sounds proceed. It was ascertained that the deeper the listening device was located in the ship the better. A small vessel is thus at a disadvantage in hearing the hell, and over-board receivers will not do.

As finally worked out the listening arrangements are simple. A small cast-iron tank is screwed on to the inner wall of the ship, being open against the ship's plates. This tank is filled with water. In it two microphones are immersed near each other, but one forward, the other more aft. One such tank holding two microphones is fixed to starboard, another to port. The sound gathered by the iron walls of the vessel passes directly to the water in these tanks, and this in turn conveys it to the microphones. The best position for the tanks is well forward, nearly in the bow, this being the most frequent presentation to the source of sound. The best position of the tank is found by direct trial and varies with various peculiarities of the particular vessel.

Leads from the microphones pass upwards to the bridge. There two telephone receivers are used for listening: one being applied to each ear. One of these telephone receivers goes to the forward, the other to the after microphone in the one tank. A switch enahles either the port or starboard tank to be put on to the telephones. A semaphore tells the sailor to which side he is listening. The operator listens alternately to the sound received on port and starboard. If the signal station lies to port the telephones when switched on to the microphones on that side are loud while the starboard microphones are mute. If the bell is right aheat both microphones speak equally loudly. For obtaining an accurate bearing of the bell it is usual to swing the ship till she is bow on to the bell as judged by the equality of the sonnd in the microphones. The course of the vessel is then the bearing of the bell.

The conditions which are most favourable to the receipt of the sounds involve the presentation of the surface of the ship where the tanks are placed towards the source of the sound. It follows that the loudness of the sound and 
the distance at which the bell is heard depend on the bearing of the bell from the ship. If the bell is right aft no sound is heard save at close quarters. In this case the stoppage of the sound is assisted by the action of the propellers in breaking up the medium. A bearing right abeam is, generally, the best. 'The sounds weakeu when well forward. Sounds coming from the opposite side of the vessel are not heard save at small distances from the bell.

While weather conditions affect to some extent the picking. up of the signals-chiefly owing to noises developed by the pitching of the vessel-the rignals are recognizable at long distances in any weather.

It is evident that of all modes of synchronous sigmalling which may be suggested, the combination of under-water sounds and wireless dot is the most free from liability to failure. True the sensitiveness is not so great as we obtain by other combinations. But facilities for receiving such signals are confined - it may be said-to the larger vessels, and these approach at such speeds that they obtain all they require if they can determine their distance from the shore to an accuracy of one quarter of a mile or even of half a mile. They should be able to effect the more accurate determination by this combination. If the radio dot is sent out at intervals of about 0.6 second the submarine bell-stroke lags the interval between two dots for each half sea-mile traversed. If the ship is 5 miles off the coast the sound lags 10 such intervals, and the bell comes in with the 10 th dot, supposing that the first dot is emitted $0 \cdot 6$ second later than the first bell-stroke. In this case the sailor counts up the dots, and so obtains the number of half sea-miles separating his ship. from the signal station. As it is quite possible to tell when the bell-stroke falls somewhere between two consecutive radio dots, estimation to the $\frac{1}{4}$ sea-mile is feasible.

In these operations the receipt of the signals is effected by listening with one ear to the bell sounds and with the other to the radio sounds, - a telephone receiver covering each ear of the operator.

In September 1911, the United States Hydrographic Department undertook an experiment on the use of synchronized signals in air, water, and ether. The signals were sent ont from the Nantucket Lightship near New York (see fig. 3, Pl. I.). The aerial sound signa!s were created by blast from a steam whistle and those in water by submarine bell. At the instant the whistle blew, a wireless tick of two or three seconds' duration was sent out, and simultancously with the making of the contact the valve of the striking. 
mechanism of the submarine bell was tripped and a stroke was given to the bell. The coincidence of all three signals was tested by observation close to the lightship.

On board the U.S.S. "Washington' the interval between the arrival of the aerial sounds and the wireless tick was read and recordert to one half second; and that between the bellstroke and the wireless to tenths of seconds. It was assumed that the velocity of sound in air at the prevailing temperature $\left(68^{\circ} .5 \mathrm{~F}\right.$.) was 1132 feet per second, and in water (at $66^{\circ} \mathrm{F}$.) 4794 feet per second. The weather was calm and hazy.

The course steered was first due West from the lightship for a distance of 8 miles, then turning and heading E.S.E., the lightship being passed on the port beam at a distance of 3450 yards. Standing on for 8 miles further she turned to the N.W., passing the lightship on the port beam at about 4600 yards ; and thence back to the lightship on a S.E. course.

At starting the whistle and bell were right astern. The bell was lost at a distance of about 2 miles, and the whistle at, it is stated, about half a mile. The lors of the sound of the whistle can only be ascribed to the phenomenon of silent areas. The loss of the bell is a consequence of the defective presentation of the receiving tanks towards sounds coming from right astem. As might be expected, the bell was not again picked up till the "Washington' turned to go eastward. It was then picked up at a distance of about $7 \cdot 6$ miles, the lag of the sonnds on the radio dots being 9.5 seconds. The sounds were then reaching her on the port bow. The whistle was not recovered till the 'Washington' had approached much nearer to the lightship -a distance of about 4 miles. Bell and whistle were held on this course till the liphtship was passed and left well astern, the bell sound being lost when the distance from the lightship was about $5 \frac{1}{4}$ miles, and the angle of approach of the sounds was $19^{\circ}$ with the course and approaching on the stern of the 'Washington?' 'This, again, is to be expected as a consequence of the lessening presentation of the receiving tanks. The whistle was held on this E.S.E. course till the "Washington' was about $7 \frac{1}{2}$ miles from the lightship. Here the whistle had the advaniage. The bell was recorered immediately on turning N.W., and when the distance was 8.6 miles. The whistle was pieked $u$, on the N.W. course when 6 miles from the lightship. The real superiority of the submarine transmission of sound is here plainly shown. Both sounds were then held till the finish.

The course of the ship and each observation are recorded 
on a chart: a zig-zag red line comnecting the determinations of distance by the bell and a similar blue line those by the whistle. Both these lines cross and recross the true course, which appears as a straight black line. The true course was. found by range-finder and compass.

The experiment is highly instructive. The outstanding features are $(a)$ the fact that both bell and whistle when heard suffice to determine the distance with fair accuracy : (b) the failure of the aerial sounds when the "Washington' was quite close to the lightship, the bell being still audible in spite of the unfavourable presentation: (c) the distance of hearing the bell being cut down to 2 miles owing to sternward presentation: (d) its audibility on favourable bearings over a wide angle to $8 \frac{1}{2}$ miles, and $(e)$ its audibility at $5 \frac{1}{4}$ miles when the approach of the sound was sternward at $19^{\circ}$ with the course : $(f)$ the maximum carriage of the aerial sounds- $7 \frac{1}{2}$ miles-is exceeded by that of the submarine bell. The ultimate limit of audibility of the latter was not reached.

The general conclusion must be that with favourable presentation the submarine sound affords a more reliable signal than aerial sound. The causes of its failure can be foretold and are not capricious. It is certain that if at any time the 'Washington' had been swung into a more favourable course the sounds would again have been heard. On the other hand the loss of aerial signals is capricious and cannot be anticipated, and swinging the ship must fail to recover them.

That the U.S. Government were satisfied with the results of this experiment is shown by the recent establishment on Fire Island Lightship, off New York Harbour, of a synchronized signal station, involving the emission of submirine bell-sounds and wireless dots.

Synchronous signalling is, therefore, in practical use. This tirst installation professes to be in a sense experimental, "although this station has proved accurate on test." Ship captains are asked to report their experience to the Hydrographic Department. The British Board of Trade has recently issued to mariners the requisite notice and descriptive particulars. "The apparatus will be in operation during fog, mist, rain or falling snow. The range of this apparatus is limited to the receiving range of the submarine bell receiving equipment employed on shipboard, and in all practical cases this is within six or seven miles. The submarine bell strikes six strokes, pause, then eight strokes once every 38 seconds." The series of radio signals begins 
about $\frac{1}{2}$ second after the first of the group of six bellstrokes. The distance is determined by counting up these radio dots until the first stroke of the six submarine signals is received. The number of dots thas determined gives the distance in half sea-miles. It will here be seen that two unsymmetrical groups of bell-strokes are emitted. This appears to have in view the certain identification of the station and of rendering it easier to first pick up the signals. The number of the lightship is stated to be spelled out by the signals. Numerical examples are added showing readings of distance to the quarter mile. In this installation the size of the radio antenna is designed to send out signals which will not be heard much beyond the range of the submarine bell, in order to avoid unnecessary interference with near-by radio stations.

We may now picture to ourselves the practical application of this system of synchronized submarine bell-strokes and radio dots installed at Fire Island. We are on board a liner going westward and-we will suppose-are deep in a fog bank. Our whistle emits prolonged and far sounding blasts every two minutes. In former years, when the present writer experienced just such conditions approaching New York, frequent determination of depth was the on!y means available for fixing with any approach to accuracy the position of the ship, and hours were thus wasted, gradually stealing closer to the land. Iset us now, however, imagine the little instruments on Fire Island busy tapping out to the mariner the knowledge he so anxiously desires to obtain. The speed of the ship is but little reduced, for ample warning by wireless dots and submarine bell stroke may be counted on. And now upon our ship the wireless operator reports to the bridge the inst wireless dots. Then the bell-strokes are picked up. There are the six-pause-eight strokes once every 40 seconds. There can be no doubt as to what he is listening to. He waits for the first of the group of radio dots and counts them up till he hears a bell-stroke. He finds that the bell-stroke falls-say-just between the 12 th and 13 th radio dot; that is to say he must divide 121 by 2 for the distance in knots. He reports, accordingly, $6 \frac{1}{4}$ miles from Fire Island Lightship, the signals being heard on the port bow. The land fall is made.

That radio signals and submarine bell could be worked reliably from a buoy, and, if desired, in combination with light flashes, seems very probable. The emission of the instantaneously propagated signals would be started by the bell-stroke. The wireless would have a range comparable 
with the carriage of the bell-sound ; the light flashes being probably of lesser range and for the use of smaller vessels which can generally approach with safety rearer to the coast owing to shatlow draught. The emission of wireless signals at intervals of one or two minutes would be quite adequate, and economy of current would be attained.

The Fessenden Oscillator has long been a potential rival to the submarine bell as a means of generating sound waves in water. But lately such developments of the Oscillator have been made that it seems highly probable that on the more important ships it will take the place of the bell. Professor Fessenden has, in short, by his recent improvements rendered possible uses of submarine signalling almost unhoped for, although often wished for in the past. On the results of the experiments claim has been made to-

(a) Incrensed radius of audibility up to 30 miles or even more.

(b) The easy signalling by Morse code over these great distances by an ordinary telegraph liey.

(c) The receipt and emission of the signals by one and the same apparatus located in the ship or lowered overboard.

To these may be added the following, provisionally on further experiments proving as successful as those already made :-

(d) The determination of depth beneath the moving vessel by echo from the bottom.

(c) The location of icebergs by refiected sound from the submerged part of the berg.

The transmission of speech over short but nseful distances is, in addition to the claims founded on experiments, a highly probable development. What these claims involve may not at first be fully realized. Even if we accept the first three only we approach the consideration of the instrument on which these are founded with considerable interest.

The new Oscillator is not in principle different from the earlier invention of Professor Fessenden. The sound generated in the water originates in the rapid in-and-out vibration of a metallic diaphragm. This diaphragm may form part of the side of the ship. Now, obvionsly, the difficulty to be overcome in making such an apparatus successful is to generate and apply a force of sufficient intensity to overcome the inertia of the diaphragm and other moving parts (weighing in point of fact over $100 \mathrm{lb}$.) as well as that of the water, in a space of time measured in 
hundredths or even thousandths of a second. In ordor to transmit 20 words per minute by code about 100 compressional waves are required per minute, and to transmit speech several thousands of waves.

This power is, of course, applied electrically, an armature being excited by a powerful alternating current having a frequency of about 500 per second.

It is remarkable that this instrument, in spite of the great inertia and accelerations involved, can act as a receiver to sound waves reaching the ship through the water; functionating then as a generator. Hence it is only necessary, when the oscillator is being used both for the transmission and reception of sound, to set over a switch with each change in the nature of the operations required. The sounds may also be received by ordinary microphone as fitted for the submarine bell. (An interesting account of the improved oscillator is issued by the Submarine Signal Company.)

In an early test the oscillator was lowered 12 feet off the Boston lightship. The signals were plainly heard by microphone 31 miles away. They have been emitted also from moving ships and heard more than 20 miles away. It is evident that on vessels and in situations where an alternating current of sufficient power is available the use of this now device possesses great advantages. For not only is the range of the sound greatly increased over that claimed for the bell, but code signals can be easily transmitted. And there are also new possibilities as regards synchronous signalling. A vessel moving at the high speed of 25 knots may learn her distance from the land, the bearing of the signal station, and hence the correct course to steer, more than an hour before she makes her harbour. Remember, too, that this information comes in in any weather. It has not to be listened for in the open but is quietly whispered in the cabin.

Of great interest, too, are the applications of the oscillator as a depth-finder and as a protection against icebergs. In both cases the reflexion of the sound and its return to the observer are used.

The depth-finder is admirably simple. Imagine a commutator-wheel with one conducting segment leading to the armature of the oscillator. Two brushes touch this wheel, one connected to the alternating current generator, and the other to the telephone-receiver. As the wheel is rotated the oscillator is excited while the brush connected with the source of current is passing over the conducting sogment. Excitation then ceases and the sound from the 
oscillator travels to the bottom of the sea, comes back by reflexion, and acting on the oscillator generates a current in it. This will be heard in the telephone receiver if the brush connected to the telephone is in contact with the segment just at the instant when the reflected sound impulse reaches the ship. The setting of the telephone brush will, therefore, determine the depth. In a depth of 8 fathoms beneath the oscillator the time for the sound to travel to the bottom and back will be about the one-fortieth of a second. The echo, according to the results of a trial made from a U.S. Revenue Cutter, may he beard in the ship withont the use of the receiver. A stop-watch used to determine the interval between the start and return of the sound afforded a good approximation to the depth.

Experimenting from the same vessel, the distance of an iceber 450 feet long and 130 feet high was determined by echo from the submerged part of the berg at various distances from one-hal mile to two and one-half miles. The echoes were not only heard in the oscillator receiver, but in the officers' wardroom and elsewhere in the ship. The distances agreed with those determined by the range-finder. The prosecution of the experiments was hindered by rough weather, the oscillator not being permanently installed but lowered overboard. The echoes were loud at $2 \frac{1}{2}$ miles. It is stated that as regards the intensity of this underwater echo, it made no difference whether the face of the berg was presented to the ship or otherwise. It must be remembered that the immersed volume of the berg was some ten times as bulky as that presented to view.

Marvellous as all this undoubtedly is, the purely sensational part of it is surpassed by the achievements of wireless telephony. The wireless telephone can speak in plain words to the sailor, telling him the name of the signal station he is approaching and warning him of his danger if he comes too close. The speaker is a machine, a dead thing, and æether waves carry the energy, translated out of its rightiul medium, through miles of wild weather, to the ship labouring far off the coast, and there it is again restored to the medium, whereby it reaches the sailor's cognizance. He listens at a telephone in his cabin or wireless room and hears the words reiterated over and over again by the machine in the lighthouse. At this latest achievement of Science, we feel inclined to say : "Hold! Enough!"

The wireless telephone is no very recent achievement. Speech has been transmitted by its means from stations in Phil. Mag. S. 6. Vol. 36. No. 211. July 1918. 
the United States to the Eiffel l'ower. The system of Dr. de Forrest is, I believe, used in the maritime application of which I am speaking. The installation is at Point Juditb at the western approach to Narragauset Bay. Here, in outline, is how this marvel is accomplished:-

A phonograpl speaks the words. It cries the name of the lighthouse or lightship into the transmitter. The system is entirely automatic. The movement of a switch starts the phonograph into operation. The voice, translated into æether waves, reaches the antenna on the ship and is there retranslated to the spoken words by a detector and telephone. No training in Morse signals is required. The sailor hears the words just as the householder hears the message in his telephone. It is stated in an account of this system kindly sent to me by the Submarine Signal Company:--" The receiving apparatus is so small and requires so little tuning that for small ships with no operator, the Captain with a few minutes' instruction could pick up and use the signals." At Point Judith " the intensity of the sound and radiation of the transmitter are so designed that ships equipped with the ordinary antenna will hear the signals the same approximate distance that the light wonld be seen in clear weather." There is heard first a voice which cries the name of the Station every five seconds. After every third repetition of the name of the Station a much feebler voice speaks the warning "You are getting closer ; keep off." This signal the sailor will only hear when close in to the lighthouse. The instrument accomplishing this marvel has been called the Radiophone. It is intended to set up Radiophones at several stations on the Atlantic and Pacific coasts.

When in addition to this instrument you fit the vessel with the wireless compass or goniometer-an instrument whereby the directions from which wireless messages are approaching the ship may be approximately determined,you have an equipment which replaces the use of the lighthouse in fog or thick weather. It must, however, be remembered that this system, interesting and womerful as it is, possesses some of the defects of the light signals. Even if the wireless goniometer gave him his angles as accurately as he obtains them by station pointer in clear weatherwhich is very doubtful-the distance indications can only depend on the strength of the wireless signal. But here the influence of atmospheric conditions in affecting the amount of absorption of the transmitted energy must introduce capricious variations. Position cannot be fixed without 
reliable distance determinations. With stations so distributed as to give simultaneous readings of angles by wireless goniometer, the seaman can, indeed, proceed by wireless alone from headland to headland, hearing the name of each proclaimed in plain language and laying his course by the use of the radio-goniometer.

It is evident that the last few years have opened up wonderful prospects to coastal navigation. And surely those voices, crying to the Mariner through darkness and storm, reassuring him and guiding him on his way, captivate the inagination beyond any other of the marvels of applied science in our time.

\section{Avoiding Collision.}

The existing rules for avoiding collision at sea have been in force for more than one generation and, it is needless to say, have done inestimable service. They date from a period when the resources of science were much less than they now are. Wireless telegraphy was unthought of, and submarine signalling, if occasionally mooted as a possibility, had not been put to any practical trial. These time-honoured rules tell the sailor what he is to do when he sights another ship with which collision may occur. In general one only of the ships may alter course, and their rolative position decides which of them is to do so. The compulsory use of certain regulation lights on vessels enables these rules to apply also to night time in clear weather.

When the weather gets thick, or fog or snow comes on, it is assumed that all methods save those of whistling and listening fail. A prolonged blast must be emitted at intervals of not more than two minutes. The ship must slow down to "a moderate speed." The great problems then confronting the sailor are to hear the sound on the other ship in good time; to locate it; and then to the right thing; at the same time letting the other ship know what he has done. The trouble is, mainly, that the relative position of the ships is difficult to determine. Sound directions are liable to deceive and in very wild weather to carry badly, or to be inaudible owing to the noise and uproar upon and around the ship. For a happy issue out of all these affictions the mariner can only trust to his vigilance, to his presence of mind, and to a considerable measure of luck. These failing him his own ship or the other ship may be lost. The 
circumstance may be such that the last factor only-luckdetermines the result.

The time has come when a complete re-consideration of the whole matter in the light of modern advances in signalling is desirable if not indeed imperatively necessary. Not that existing rules need be abrogated. In close traftic these may well prove essential, especially when small coasting craft are concerned. Nor are the modern methods and the older ones mutually exclusive. The chief danger, however, is really in the ocean routes where high speeds must be maintained and the risk taken. There is little doubt that with the compulsory use of such methods of signalling as are now available high speeds could be maintained and very little risk remain. It is irrational to suppose that educated officers who have been trained in far more difficult navigational methods could not use the methods we have to consider. The actual taking in of the signal will probably always fall to the wireless operators on board : men who hold certificates of proficiency in dealing with such matters. Alone the interpretation of the signals lies with the Officer of the Watch. And as a fundamental regulation the Board of Trade would require continuous watch in the wireless room on all ships during thick weather.

With the advent of wireless telegraphy at sea-due in the first instance to Admiral Sir Henry Jackson-the sailor inherited a means of speech which is available in almost every state of the weather. And in submarine signalling yet another mode of communication is open to him, whereby ship may speak with ship over distances from 6 to 20 or more miles in all weathers. Directions may be determined approximately by both these methods of intercommunication. But when the problem of avoiding collision in all circumstances is fully considered it will, I believe, be recognized that determination of distance-that is, the distance between the vessels-is an essential element for safety.

And this brings us back to synchronous signalling as the only means whereby distance from ship to ship can be safely determined.

There is no doubt that the combination of submarine sound signal and wireless signal is the most reliable one available. True, the sensitiveness is no more than will determine the distance to the half-knot although the quarterknot may be estimated. Practice would do a great deal in such a matter, as everyone who has observed small time intervals in the laboratory soon finds. And it is also to be remembered that we are dealing with ships moving at 
considerable speeds; so that they may cover a half-knot in $1 \frac{1}{2}$ minutes, or even in one minute when the relative velocities of the vessels are taken into account. As the mutual avoidance of such vessels cannot safely be left to less than the last minute, the sensitiveness of the method is quite adequate to the use required of it.

It will not, probably, be superfluous to say something as to the available means of submarine signalling between ship and ship as apart from the mere reception on the ship of a submarine signal sent from the shore. The latter subject we have already considered, but nothing has been said as to the emission of submarine signals from the ship.

There is first of all the use of the bell. The sound of the bell may normally be taken as carrying 7 or, at least, 5 miles. It gives a sharp, unmistakable sound; and the apparatus concerned has the advantages of compactness and simplicity of construction. Its application to ships would appear to incolve the provision of a recess somewhere in the ship's bottom. The hottom is assuredly the best position; for the radiation of the sound is then not interfered with in any direction by the ship herself. The provision of the recess is a protection to the bell, which is supposed to be raised into the recess and housed therein when not required for use. This construction has, I understand, already been applied to submarines.

The rival sound-signaling machine is the Fessenden Oscillator. This is an instrument for which a much greater range is claimed, and is, in addition, highly adapted for transmission of code signals.

Whether bell or oscillator are employed we may suppose the signals completely controlled from the room of the wireless operator and the easy possibility of securing mechanical control of the signals, so that by clock-work their emission mar be accurately regulated and timed to the signals sent ont by wireless in the otherial medium. We may, in short, discuss the use of synchronous signalling in avoiding collision, with our minds at ease as to the complete practical possibility of putting the method into operation. Both the bell and the oscillator have, in fact, already been applied to moving vessels.

We shall assume that ships navigating in fog or thick weather are required by (future) Board of Trade regulations to emit a certain low-power wireless signal at intervals, say, of 5 minutes, and that when two ships become aware of each other's signals they may, if they deem it necessary, exchange the usual code signals giving course and speed. The 
communication of these data is a simple matter. It forms a familiar part of the preliminary correspondence of a ship station with a coast station after the latter has been called. Both are numbers. The course is given in degrees from $0^{\circ}$ to $360^{\circ}$ reckoned from North round by E. S. and W.; i. e., clockwise. The speed is signalled in nautical miles per hour. The signals are emitted at the rate of some 20 words per minute, or a word of five letters in 3 seconds. Thus, to fix our ideas, we may suppose that ship A learns that ship $\mathrm{B}$ is proceeding South $\left(180^{\circ}\right)$ at $16 \frac{1}{2}$ knots, and $\mathrm{B}$ learns that $\mathrm{A}$ is holding a course NE. $\frac{3}{4} \mathrm{E}$. (say $53^{\circ}$ ) at a speed of 11 knots.

Additional to these means of dealing with the problems presented by methods of averting collision, it must be recalled that in the radio-goniometer or wireless compass and in submarine signals the marincr possesses a means of finding the bearing of another ship with approximate accuracy.

Now there are four criteria which enable the sailor to say in advance whether a particular ship in his locality, but assumed to be quite invisible to lim, is moving so as to collide with his ship or whether she is not. Let us first write down what these criterii are.

If two ships, $A$ and $B$, are moving so as to collide :-

(1) The nutual bearings of the ships are determined by and deducible from the courses and speeds of the vessels.

(2) The rate of mutual approach of $A$ and $B-\mathrm{i}$. e., the relative velocity-is fixed and determined by the courses and speeds and is the maximum possible for these. courses aad speeds.

(3) The bearing of ship from slip is constant and invariabie up to the moment of collision.

(4) The rate of mutual approach remains constant up to the moment of collision.

It is convenient to first consider those two criteria which are dependent u! on and deducible from the prevailing courses and speeds; $i$.e., the bearing which indicates threatened collision and the relative velocity which indicates threatened collision. How may these two criteria be used by the mariner? The matter may he stated thus:-

With the knowledge in his possession of the course and speed of each ship the navigator, by simple methods to be presently described, determilies what the bearing of the ships from each other must be if collision is threatened and what the relative velocity or rate of mutual approach of the vessels must be if collision is threatened. These criteria are 
decisive on the question of collision or no collision. $\mathrm{By}$ comparing what may be called the "danger bearing" and the "danger rate of approach" with the actual bearing and actual rate of approach he obtains complete assurance on the serious issue before him. Thus, for example, with the courses and speeds cited above the navigator finds that $B$ will bear NNE. from $A$, and A will bear SSW. from B, and the rate of approach of the ships towards each other will be 24 knots per hour: if collision is threatened and only if collision is threatened.

Accordingly, the navigator can tell whether collision is threatened or not $(a)$ by abserving the actual bearing of the other ship or (b) by determining the rate of approach of the ships.

A very large percentage of cases presented to him may be at once dismissed by determination of bearing. The bearing of the other ship may be determined by radio-goniometer or by submarine signalling. I do not think the accuracy of such determinations will suffice for all cases of threatened collision. This point must be further considered later. But fairly accurate determination of bearing would suffice to rule out many cases. Suppose, for instance, in the case of $A$ and $B$ above, that the bearing of $B$ from $A$ is observed to be more than a point divergent from NNE., $i . e$. from the danger bearing; it is then certain that collision will not occur. The Officers on A and B might exchange a short code signal expressing understanding on this point. And, of course, both know that the existing courses and speeds which insure safety must be carefully held and maintained.

But if there is any close approximation of the observed bearing to the pre-determined danger bearing, then the determination of the rate of approach of the vessels would be entered on at once. For one thing there is nothing in the observation of bearing to tell the navigator the distance of the other ship. Guessing this distance by the strength or intensity of the signals may prove seriously inaceurate. And with no knowledge of distance the sailor is placed in a very unxious position, and one which may compel him to alter course quite needlessly - as we shall see.

The determination of the rate of approach is got by successive determinations of the distance separating the vessels. Now, knowing the danger rate, the sailor can tell from the very first determination of distance when collision would be due, supposing it to be threatened. And this tells him whether he must act at once or whether be has plenty of time. He knows, in fact, "there are so many minutes to go 
before collision can occur." The second determination of distance compared with the first tells him whether the actual rate of approach approximates to the danger rate of approach. If it does, and continues to do so on a f'ew more observations by synchronous signal, one of the ships must give way in good time.

In short, the procedure whereby collision may be averted in all weather involves:-(a) exchange of signals, wireless or submarine, giving courses and speeds : $(b)$ finding from these data the "danger bearing" and "danger rate of approach": (c) ascertainment of the actual bearing and rate of approach.

These operations, even if called for in their completeness, are simple and easily carried out: characteristics of value under conditions which may involve hurry and anxiety. It is necessary now to consider the successive steps more in detail and to enter briefly on the principles upon which the operations are based.

What are the conditions determining collision? Suppose ships A and B are moving on paths which intersect. Then the conditions for collision involve that $A$ and $B$ are, at a given instant, at distances $\mathrm{AO}$ and $\mathrm{BO}$ from the point of intersection, $O$, such that their speeds will carry each ship over the respective distances $A O$ and $B O$ in the same interval of time. In other words courses, speeds, and positions are involved. When these three factors are such as to lead to collision then is the following important condition fulfilled:- the direct distance between the ships will decrease at the maximum rate possible for the given courses and speeds. In other words, the relative velocity is a miximum for the courses and speeds. This is evident, for its entire velocity is then carrying each ship directly towards the other ship at the only point where they can meet : that is, the point of intersection of their courses.

We may reverse the steps of our reasoning and say, if the relative velocity of the vessels is the maximum for the courses and speeds, then is collision sure to occur, and if it is not the maximum, collision cannot occur: the ships will pass clear.

In order to find the maximum relative velocity or "danger rate of approach" of the ships, knowing the courses and speeds we may construct a triangle of velocities. Two of the sides of the triangle are parallel with the courses; and the lengths of these sides are proportional to the speeds of the ships. 'The third side, completing the triangle, gives us, now, by its direction the bearing of $A$ from $B$ and of $B$ from 
$A$, and by its length the relative velocity of $A$ and $B$. The conditions are now the same as if $A$ was at rest and $B$ moving with this velocity towards A. Evidently the distance between them will diminish at the maximum rate, for B is moving straight towards A. But this procedure for finding the maximum rate of approach is one which we cannot expect the seaman to carry out in the urgent circumstances of his position. We suppose, instead, that he is provided with a simple instrument which may be named a Collision Predictor.

This instrument (Pl. I. fig. 4) consists of a circle upon which compass bearings and angles measured from $\mathrm{N}$, clockwise, are engraved. It carries two limbs, $a$ and $b$, which rotate independently about the centre; which are divided to read speeds in knots per unit time; and which can be clamped in any position. An arm, $c$, is piroted upon a sliding piece or cursor, which can be slipped along the limb $a$. This arm carries centrally a tramsparent divided scale, as shown.

When the sailor is given the courses and speeds he proceeds as follows:-One limb, say $a$, he sets round to the course of his own ship A. The other, l, he sets to the course of the other ship B. He then slides the cursor along $a$ till it reads on $a$ a number which is proportional to the velocity of his own ship A. He next inflects the arm $c$, so that it intersects the limb $b$ at a distance from the centre proportional to the speed of the other ship B. He has now constructed his triangle of velocities, and he reads on the transparent scale of the arm $c$ the relative velocity he seeks: that is, be reads on it the relative velocity when collision is threatened: which, as we have seen, is the maximum for the courses and speeds.

It is convenient to read on $c$ the rate of approach or relative velocity in terms of the amount by which the direct distance separating the vessels diminishes in two minutes; or one minute, according to the interval separating the observations of distance by synchronous signalling. I assume that this is 2 minutes. "Then, reverting to our example, baving set the limb $a \mathrm{NE} \cdot \frac{3}{4} \mathrm{E}$., and the limb $b$ due South and slipping the cursor along $a$ till it reads the speed of $\mathrm{A}-i$.e., 11 knots-and inflecting $c$ to read on $b 16 \frac{1}{2}$ knots (i.e., the speed of $\mathrm{B}$ ), the navigator finds that the scale on $c$ is cut by its intersection with $b$, at the reading 0.8 . What is this? It is the distance in knots by which the ships A and $B$, in our example, must approach towards one another in two minutes if collision is threatened, i.e., eight-tenths of 
a knot. This is the danger rate of approach; and is the same as 24 knots per hour as given alove.

We have incidentally found also the danger bearing. The $\operatorname{arm} c$ in fact points from $A$ to $B$; that is, if we moved it parallel to itself till it crossed the centre of the divided compass circle, then it would read the bearings required. It is easy to arrange for the attachnent of a parallel motion to $c$, which can be moved so as to cross the centre of the divided circle and read the bearings. In the example chosen, for instance, it shows that $B$ bears NNE. from $A$, and $A$ SSW. from B if collision is threatened. We here use the instrument as a means of constructing a triangle of displacements rather than of velocities: which is obviously legitimate. 'Thus the narigator by merely setting the limbs on this instruinent to the courses, and setting the arm $c$ to the speeds, obtains the danger rate of approach and the danger bearing.

It may be helpful to some to consider a quite simple case. Suppose the courses of the ships are directed exactly opposite. Suppose $\mathrm{X}$ is going due south and $\mathrm{Y}$ is going due north. Let the speeds be 20 and 10 knots respectively.

Now the lact of the courses being opposed does not involve collision. The bearing of $\mathrm{X}$ from $\mathrm{X}$ or of $\mathrm{Y}$ from $\mathrm{X}$ may be anything at all so far as courses are concerned. For instance, the ships might be passing abeam of one another. But there is one particular bearing of $X$ from $Y$ and one of $Y$ from $\mathrm{X}$ which denotes collision:- - when $\mathrm{X}$ bears north from $\mathrm{Y}$ and $\mathrm{Y}$ bears south from $\mathrm{X}$. The ships are then approaching end on and collision is threatened. These are in this case the dunger bearings of ship from ship.

Again, the rate of approach of $X$ and $Y$ may be anything at all, within certain limits, so fur as courses and speeds are concerned. Thus the distance between the vessels wonld be shortening quite slowly supposing $Y$ bore somewhere forward of the beam of $\mathrm{X}$; or, it might be, actually increasing if $\mathrm{Y}$ bore aft of the beam of $\mathrm{X}$. It is evident that only when the vessels are approaching end on is the distance decreasing at the naxinum rate: that is, the relative velocity is a maximum ; and it must amount to $20+10=30$ knots. This is the danger rate of approach, and it is evidently associated with collision. If observations of distance are taken every two minutes this rate would involve the distance between the vessels diminishing at each observation by one knot.

We see then that there is a danger bearing and a danger rate of approach peculiar to collision. The Collision Predictor applied to the above case would give the danger 
bearings as north and south and the danger rate as one knot.

As we have already seen, the knowledge of the danger bearing may rule out the possitility of collision. For if the actual bearing is decisively different from the danger bearing there cannot be collision. By radio-groniometer-an instrument we must refer to again later on-the bearing may be found, at least approximately. Or by submarine sounds an approximate bearing may be taken. If the Fessenden Oscillator is carried on the ships the bearing could be determined while yet 10 or more miles separated the vessels. If the bell is carried the bearing conld be found some 6 or 7 miles away under normal conditions. The determination of the bearing will, probably. be the first procedure. But we will suppose that the bearing as observed - however determined-is doubtful ; that it cannot be safely discriminated from the danger bearing. And as the sailor knows not with any certainty at this stage the distance separating the vessels, he regards it as unsafe to undertake prolonged observations of the bearing, and decides on finding the distance and the rate of approach.

When he determines on this he makes a code signal announcing to the other ship that he is about to find the distance by synchronous signals. If this is announced by $A$, $B$ prepares to listen. When at length B picks up the oscillator or bell she teils $A$ the distance as so many miles. This first observation of distance assures to the sailor a knowledge of the time at his disposal. For supposereverting to our example-that B says "our distance is 5 miles." Then both on A and B it is known that crllision cannot occnr sooner than 12 minutes from that instant. For on $\mathrm{A}$ and $\mathrm{B}$ it is already known that the danger rate or maximum rate of approach for the courses and speeds is 0.8 knot in 2 minutes, or 0.4 knot in 1 minute. Hence we have to divide 5 by 0.4 to get the interval in minutes before collision can occur ; and this gives $12 \frac{1}{2}$ minutes. In this way the sailor knows at the earliest moment at which the submarine signals are audible from ship to ship bow much time is available for further observation.

Two minutes after the first observation of distance, a second synchronous signal is sent out-say from $A$-and $B$ says "our listance is 4 miles." This looks like danger. For there is some error certainly seeing that the approach cannot be so much as 1 mile in 2 minutes. There is now 10 minutes to go and there is no reason why several more distance determinations should not be made. The emission 
of the signals is automatic. On receiving the third signal B says "our distance is $3 \frac{1}{2}$ miles." This also is evidently quite in keeping with the danger rate. There is now 8 minutes to go. On the 4th signal the distance falls, we will suppose, to 2.5 miles with 6 minutes to go. The danger may now be regarded as established. But there is no reason why further signals should not be exchanged, before B gives way to $\mathrm{A}$.

The successive observations of distance may be recorded on paper as they come in, and be compared with the successive danger distances written down upon the finding of the initial distance. Or they may be observed and followed one by one on the Collision Predictor. Taking the former method first we may suppose a ruled sheet with columns set out to take the figures thus :-
Course A $53^{\circ}$.
Course B $180^{\circ}$.
Speed A 11.
Speed B $16 \frac{1}{2}$.
Danger Bearing NNE.
Obs. Bearing NNE.
Danger Rate $0 \cdot 8$.

\begin{tabular}{ccccccr} 
Sig. & & $\begin{array}{c}\text { Danger } \\
\text { Distance. }\end{array}$ & \multicolumn{3}{c}{$\begin{array}{c}\text { Observed } \\
\text { Distance. }\end{array}$} & T. \\
1 & $\ldots$ & & $\ldots$ & 5 & $\ldots$ & 12 \\
2 & $\ldots$ & $4 \cdot 2$ & $\ldots$ & 4 & $\ldots$ & 10 \\
3 & $\ldots$ & $3 \cdot 4$ & $\ldots$ & $3 \cdot 5$ & $\ldots$ & 8 \\
4 & $\ldots$ & $2 \cdot 6$ & $\ldots$ & $2 \cdot 5$ & $\ldots$ & 6 \\
5 & $\ldots$ & $1 \cdot 8$ & $\ldots$ & $2 \cdot 0$ & $\ldots$ & 4 \\
6 & $\ldots$ & $1 \cdot 0$ & $\ldots$ & $1 \cdot 0$ & $\ldots$ & 2 \\
7 & $\ldots$ & $0 \cdot 2$ & $\ldots$ & & $\ldots$ & 0 \\
8 & & & & & & \\
9 & & & & & & \\
10 & & & & & &
\end{tabular}

In the two minutes interval between the 1st and 2nd observation of distance the Officer of the Watch fills in columns 2 and 4 .

We assume here readings typieal of threatened collision. If collision is not going to occur the observed distances will disagree with the danger distances already written down. In what way will they differ? We have seen that the danger rate is the maximum for the courses and speeds. If then collision is not threatened the vessels will be approaching more slowly than if collision is threatened. The difference between the rates will give rise to a cumulative increase in the distance separating the vessels. As the observations progress it will be found that danger distances and safety distances differ more and more widely. 
And there is another reason why this difierence between danger entries and safety entries in the table will increase. We must anticipate here the reasons for the 4 th criterion denoting collision. It is easy to see that only in the case of coming collision is the velocity of approach constant. If we place $A$ in the centre of a series of concentric circles described, say, at radial distances of one knot; then if collision is coming $\mathrm{B}$ is traversing these circles radially in its advance towards A and her velocity of approach is constant. But if $B$ is not aiming for $A$ she is not advancing radially. Her velocity of approach towards $A$ cannot be constant. When she is far from $A$ her rate of approach to $A$ is greater than when she draws near. When she gets abeam of $A$ there is a moment when there is no further diminution of distance. The relative velocity is then zero. After this $\mathrm{B}$ begins to recede from $A$.

Now this must come out in the successive observations of distance between $\mathrm{A}$ and $\mathrm{B}$ and will tend to further accentuate the difference between danger and safety readings of distance. This cumulative and increasing distinction in the character of the two sets of figures-those which have been written down on the assumption that collision is threatened and those which come in if it is not threatened-is a feature of much value. It tends to redress the want of sensitiveness of the readings and to distinguish true from fictitious safety. Danger readings cannot be confounded with safety readings as observations multiply.

There are advantages in keeping the observations on paper as described above. 'There must be ample time for several observations if a good look-out has been kept. The observations are actually made by the wireless operator. The Officer of the Watch has only to write them down. His own ship's course and speed are already entered. The fact that the siguals are sent out and read by one individual, who has no responsibility beyond reporting them, and that they are interpreted by another, is an element of safety, for it leaves each operator free to give his attention to one matter only.

The Collision Predictor is intended to give the navigator the means of following the approximation of the two ships step by step as the readings of distance come in, and permitting him to appreciate the imminence of danger in case of threatened collision by merely looking at the instrument.

These functions it accomplishes in virtue of the fact that if the cursor is slipped along the $\operatorname{limb} a$, keeping the arm $c$ clamped on the cursor at the angle determined by the first 
setting of $c$, the gradual mutual approach of the ships is traced out on the scale carried by the arm $c$ at its intersection with the scale on $b$. Thus, suppose when the second reading is made we move the cursor along $a$ a total distance corresponding to the run of $\mathrm{A}$ in 4 minutes, then the arm $c$ shifts on the limb $b$ to the corresponding run of $B$ (as it moves parallel to itself) and twice the danger distance is read on $c^{*}$. Now if we have a mark on the arm $c$ at the reading of the initial distance separating the vessels-i.e. 5 miles-then as we shift forward the cursor at each synchronous signal, that is to say at intervals of two minutes, we can by simply looking at the rearling on $c$ at its intersection with $b$, observe upon it the total distance which has so far been run and the distance which remains to be run if collision is really threatened. For example, if collision is actually approaching, in the first position of $c$ we read on it 0.8 knots as run and 4.2 knots still to run. In the second position 1.6 knots run and $3 \cdot 4$ knots to run, and so on. The navigator compares these readings one by one with the actual readings of distance coming in. If they show a tendency to sustained agreement he knows for certain there is danger, and by a glance at the scale on $c$ he infers how much time remains before collision can occur. He has, in the still remaining length of the scale on $c$, a visible and tangible indication of the time left to him for action; and with each reading a simple and definite mechanical operation has to be effected which necessitates his attention being fixed on the lie of the two ships relatively to each other. If he holds the Collision Predictor in its true compass position he sees at once the direction in which the other slip is approaching, this being the direction in which the arm $\mathrm{c}$ is pointing, and at the same time he has indicated on the arm $\mathbf{c}$ at once the distance separating the ships and the time taken to cover this distance. It is like as if he followed the approach of the vessels upon a chart.

Incidentally we may observe here that the Collision Predictor finds a use even in clear weather for averting collision. For suppose two ships sighting each other and, uncertain as to the risk, exchange courses and speeds. 'Then the Predictor tells immediately the danger bearing. If the ships show that bearing towards one another then is collision threatened. Otherwise there is safety.

The foregoing description, embodying as it does an account

* 'Ihis is the position of $c$ as shown in the figure. 
of an unfamiliar instrument, may create the impression that the proposed system of averting collision is one involving rather complicated operations; and these too at a time when simplicity and clearness of procedure are above all desirable. In order to show how unlounded this impression is we shall now follow the nocessary steps as they would be taken on an adequately equipped ship in order to ascertain if there was risk of collision with another vessel. We may continue to call our own vessel $A$ and the other vessel $B$.

The scene is once more in the North Atlantic. The weather is thick and night falling. Vision is restricted to a couple of ship's lengths. The Officer of the Watch has at hand a Predictor which is already set to the course and speed of his own ship.

The operator in charge of the wireless room has started into action a clockwork contact-maker which automatically sends out, periodically, the wireless fog signals required by (future) Board of Trade rules.

Presently he hears the characteristic radio signals of another vessel. He calls the other ship; communicates his own course and speed and learns hers in exchange. These he reports at once to the Officer of the Watch who adjusts the other limb of the Predictor accordingly, and reads forthwith the danger rate and danger bearing proper to the courses and speeds of the two vessels.

Meanwhile the wireless operator has signalled to the other ship asking for signals whereby the bearings may be determined. He makes an estimate of the bearing; informs the other ship "You bear NNE."; and then reports this bearing to the Bridge.

'The Officer of the Watch is now able to say right off that the signals must be continued. For on comparing this bearing with the danger bearing he perceive's that they are indistinguishable. On board the other ship the same decision is come to.

Our ship now signals to B, by code, "Bearing dangerous : prepare to receive distance signals." Then when B acknowledges this the wireless operator on our ship sets in operation the automatic emission of synchronous signals. These continue to be emitted till B reports "Distance 5 miles."

When this is reported to the Bridge the Officer marks the arm $e$ of his Predictor at the reading 5 miles, and makes in his own mind an estimate of the minutes still to run before collision can occur. He finds there are 12 minutes. He may note the time or start a stop-watch. 
After 2 minutes $B$ gets the second distance signal and tells A "Distance 4 miles." And the Officer on A sees that this also points to danger, for the distance of approach, as observer, obviously has an error of excess and may easily represent the danger distance of 0.8 mile. And in this way he continues to compare the successive announcements of distance with the readings he gets on his Predictor by setting forward at each announcement the cursor on $a$ the distance which A travels in 2 minutes.

All this time he has a clear mental picture of where $B$ is. He can point to her compass direction and say she is there at such a distance. Finally B alters her course so as to pass clear of $\mathrm{A}$ and lets $\mathrm{A}$ know what she has done. The danger is over.

It is not improbable that the future extension to large numbers of vessels of the powers conferred by recent inprovements in submarine signalling will result in a considerable amount of the signalling between vessels being carried out by this means : in this way reducing the number of wireless messages required.

We shall now consider the use of the 3rd criterion-that which seeks to foretell threatened collision by observation of the constancy of bearing. This criterion does not involve a knowledge of the courses and speeds of the vessels.

The wireless goniometer-which in late years has been much improved -is claimed to afford a means of finding the direction whence a wireless message proceeds, with much accuracy; and this even with the use of considerable wavelengths. It is difficult to discuss these claims or to pronounce on how far they may extend to conditions of hurry, anxiety, and bad weather. Readings to a single degree have been claimed. The polar diagram of the energy transmitted by the Bellini-Tosi Directive Transmitter shows that some 10 or 11 degrees from the maximum of 88 microvolts the reading may be still 86 microvolts. Taking the distribution of intensity, when the system is used as receiver, to be similar, it would appear that the loudness of the sounds must vary but slowly near the maximum. The setting depends entirely on the discrimination of the direction of loudest telephonic sound. Most of us find difficulty in determining maxima when the senses, either of hearing or sight, are appealed to quantitatively and by consecutive impressions.

There must apparently exist a similar bar to attaining reliability of goniometric readings in the case of finding bearings by submarine signals. And the fact that an altered course must, in general, be held while the bearing is 
being watched is a serious objection to the use of submarine signalling for the purpose now in view. I refer to these difficulties because prima facie one might think that by merely determining the constancy of bearings by wireless goniometer or submarine signals the danger of collision can be always foretold and averted.

The principle involved in this method is familiar to every sailor. If the bearing of B from A is steady, collision is threatened. Represent the courses of $A$ and $B$ by inclined lines, intersecting at $O$. Now suppose that A runs the distance $\mathrm{A} \mathrm{O}$ in the time that $\mathrm{B}$ runs the distance $\mathrm{B} O$ : then collision must ocenr. And it follows that when $\mathrm{A}$ has run half the distance $\mathrm{A} \mathrm{O}, \mathrm{B}$ must have run half the distance $\mathrm{BO}$. If we join the simultaneous positions of the two ships we get, therefore, for the bearings lines which are parallel. That is, the bearing of ship from ship remains constant.

Even when used in clear daylight it is of ten objected to this method:- "While you are looking for a change of bearing the ships may collide." And the answer sometimes given is "there is no other method." Now, whatever may be said against this objection when the sailor can guess his distance from the other vessel by visual observation, it must be remembered that the proposed use in this way of the wireless goniometer leaves the sailor without any reliable estimate of distance. For the strength of the wireless signals must afford but a doubtful estimate of distance. They suffer not alone from instrumental sources of variation but from variations, due to atmospheric causes, quite ont of the control of the operator to alter or to predict. See on this subject, more especially, the observations of Admiral Sir Henry Jackson which showed a capricious reduction of carrying power from 65 to 22 miles ; or again, those of Captain Wildman who obtained frequent successive variations in audibility of 1 to 5 and rising to 1 to 10 or even more. The cause of these variations may most probably be traced to changes in the conductivity of the atmosphere due to mist, spray, etc., whereby variations in the absorption of the energy of the electric waves are brought about. Judging from these observations any dependence on the strength of wireless signals as giving an estimate of distance must be attended with danger ; just as much as judging the distance of a light by its brightness.

The wireless compass may indeed under certain conditions, in addition to other inestimable benefits conferred by it upon the sailor, be a valuable means of discriminating between safety and danger. For if there is a rapid Phil. Mag. S. 6. Vol. 36. No. 211. July 1918. 
alteration of bearing there must be safety. The question is : can it always be reliably employed? It is a fact that just when the courses of the vessels are so directed as to cause the ships to rapidly approach one another, there may be only a small ehange of bearing in a given time; and for the sailor to spend valuable minutes in setting the wireless compass to the loudest sound in the telephone when the ships are rapidly approximating one towards the other, and when it is not known for certain whether 10 miles or 3 miles separate them, is not a safe procedure. The complete and final solution of the problem of collision would appear to involve the determination of the distance separating the vessels. Otherwise the navigator must make his observations under conditions of anxiety ; and in the fear lest worse should happen must frequently be driven to alter needlessly the course of bis ship.

The 4th criterion-that foretelling collision by constancy in the rate of approach, as in the case of the method by constancy of bearings, does not involve knowledge of courses and speeds. But it possesses the very great advantage of keeping the sailor informed all the time of the distance separating the vessels ; obviously an important element of safety and conducive to the peace of mind of all concerned.

The application of this method involves simply the periodic emission from one of the ships of synchronous signals, the other ship receiving them and reporting the distance. Or each ship may alternately emit the signals and make its own observations of distance. When $A$ hears the regulation fog signals of $B$ the synchronous signalling is commenced and the signals sent out, say, at intervals of two minutes. Or the method might be applied under Board of Trade regulations enjoining the periodic emission of synchronous signals in thick or foggy weather. When the vessels come within hearing of the submarine sounds the Officer writes down the distances as his wireless operator reports them to him. If they continue to show a constant rate of approach even when the vessels draw near one another there is danger. If the rate of approach diminishes there is safety. If the vessels are approaching so as to pass close to one another the change of rate will be very marked as the distance diminishes. The most valuable feature of this method is that the sailor knows all along what time must remain for action supposing collision is really threatened. A rough determination of bearing completes his observations and tells him how he must act.

Trial of all these available methods should be made by the 
Authorities and rules framed according to the results of experience so obtained, dictating to the mariner when and under what conditions one or the other method is best employed.

The problem presented when three vessels are in the area of audition requires careful consideration and would involve special Board of Trade regulations. Generally we must. suppose the entry of a third ship, C, into the area occupied by $A$ and $B$ and while the latter were exchanging signals. It would seem reasonable for $C$, under these circumstances, to have to keep out till $A$ and $B$ are clear of one another. Again, while $C$ is waiting for the decision between $A$ and $B$, she must be restricted as to wireless and submarine signals if confusion is to be avoided. She might be restricted to the emission of the aerial sound signals now in vogue. 'These could not create confusion with the other signals. And when, finally, she enters on an exchange of signals with the other ships, it should be a rule that each vessel emits her distinguishing signal in conjunction with her other signals, so as to avoid confusion as to the origin of the signals.

If such general rules were observed there does not seem to be any serious difficulty in conducting the signalling between all three vessels. A fter exchanging courses and speeds C sends out "bearing" signals and A reports thus : " $C$ bears from A ...." and B reports : " $C$, bears from B . . . ." The Officer on $C$ now finds, using two Predictors, that he is clear of $A$ but not certainly of 13 . This is also known on $\mathrm{A}$ and $\mathrm{B}$. C makes sure of this by saying " $\mathrm{C}$ is clear of $A$," and A replies "A is clear of ( $y$. " The signals are now restricted to $C$ and $B$. After this all proceeds as before. When the time for giving way arrives the ship which is giving way takes account of the position of $A$. The latter is probably quite clear, but whether she is or not her position would be sufficiently known to $\mathrm{B}$ or $\mathrm{C}$ to avoid risk attending alteration of course or speed.

The congress of more than three vessels must be rare. The difficulties involved can only be met by clear and definite rules framed by experienced seamen.

One thing stands out clearly from our review of available methods : Modern improvements in signalling may be utilized to reduce the risks of collision enormously, no matter what the circumstances. Future developments of wireless telephony may even further simplify the sending and receipt of signals. A vessel's distinguishing signal may be her own name dictated from the phonograph. In fog and thick weather she proceeds over thn ocean calling her own name at 
regulated intervals; and at longer intervals she cries, to all whom it may concern, her course and speed. All possible. courses and speeds might be dictated from two phonographs. Timed with these wireless announcements she sends out submarine signals also which enable ships 10 or 20 miles a way to estimate her distance. She is as it were surrounded by an aureole of radiations transmitted both in matter and other, proclaiming to such other vessels as enter that anreole what she is ; how far off she is; where she is going to ; and at what speed she is approaching or receding.

This is no fancy picture-It could be made reality to-day. And doubtless the time will come when it will be made reality. The fabled wonders of Jason's Argo fade to common-place compared with the accomplished wonders of our day. 'The miraculous gifts of Lynceus were not so marvellous as. those powers of vision and audition which Science confers. upon the sailor.

II. Variably-Coupled Vibrations : III. Both Masses and Periods Unequal. By Edwix H. Barton, D.Sc., F.R.S., Professor of Physics, and H. Mary Browning, B.Sc., Lecturer and Demonstrator in Physics, University College, Nottingham*.

$$
\text { [Plates II.-V.] }
$$

\section{Contents.}

I. Inthoductron $\ldots \ldots \ldots \ldots \ldots \ldots \ldots \ldots \ldots \ldots \ldots \ldots$

II. Theory of General. Case for Double-Cord Pendulum.. 38. Equations of Motion and Coupling.

Solution and Frequencies.

Initial Conditions.

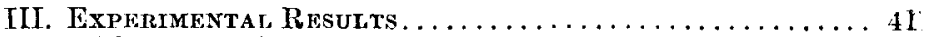

Masses. Lengths.

$20: 1 . \quad 4: 3$.

$20: 1 . \quad 9: 8$.

$20: 1 . \quad 3: 4$.

Quenched Spark.

IV. Portakle Apparatus $\ldots \ldots \ldots \ldots \ldots \ldots \ldots \ldots \ldots$

V. Covpring Graph for Cond and Lath Pendulum . . . . 46

VI. Possible Furthen Work. ................... 47

\section{Introduction.}

$1^{\mathrm{N}}$ the work described in previous papers $\dagger$, the doublecord pendulum was experimented with : (1) when the masses of the bobs and the periods of vibration of the-

* Communicated by the Authors.

† Phil. Mag. [6] vol, xxxiv. no. 202, pp. 245-270 (Oct. 1917); Phil. Mag. [6] vol. xxxv, no. 205, pp. 62-79 (Jan. 1918). 
Fig. 1.
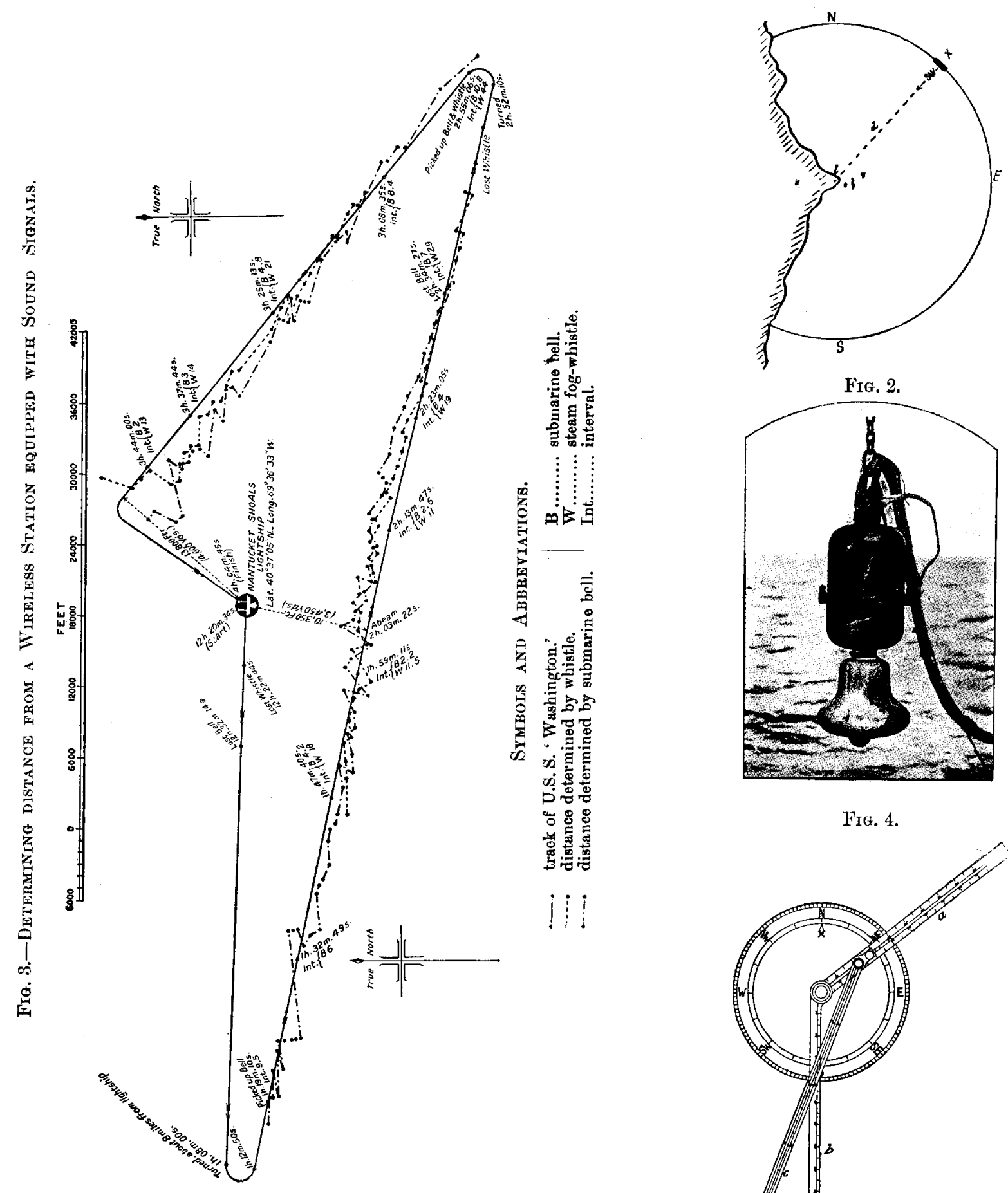

FIG. 4.

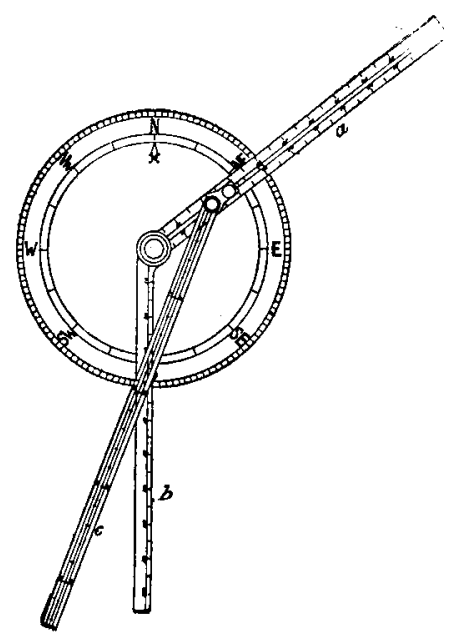

